\title{
E-Commerce Disruption: Impact and Challenges Going forward.
}

\author{
Dr. Kiran S Nair, Dr Ambili Sunil \\ Assistant Professor of Management, Abu Dhabi School of Management \\ Abu Dhabi, United Arab Emirates, Assistant Professor, Department of Business Administration \\ Emirates Canadian University College, UAQ, UAE
}

\begin{abstract}
The research paper analyses the trend and pattern of new technologies in today's E-Commerce industry and its implication on the growth of the online business. The technology transformation from web-based marketing to E-Commerce drones have been systematically analyzed. The data on the technological development collected from the secondary sources and forecasted business development by 2030. The Trend method has been used for data analysis.
\end{abstract}

\section{Objectives of the study}

$>$ To understand the new technological trends in E-commerce

$>$ To evaluate and forecast technological development in E-commerce.

\section{Research Questions}

How this E-commerce has been evolved as a major form of retail sales during the last decade?

$>$ What are the major terms and terminologies of E-commerce?

$>$ How this development has affected retail sales?

$>$ What is the trend of growth of E-Commerce technology in the world?

$>$ What would be the forecasted results of or the future of E-Commerce technologies in influencing the E-retail business? 
International Academic Conference on Management \& Economics

\section{Methodology}

The secondary data has been collected from various sources for a period of 10 years and it has been analyzed using two methods viz., Growth index calculation by using the following formula $\frac{(\mathbf{G t})-(\mathbf{G t}-\mathbf{1})}{(\mathbf{G t}-\mathbf{1})}$ and a trend line has been fit by using the following equation $\mathbf{Y}=\mathbf{a}+\mathbf{b X}$.

\section{Results and conclusion}

It is been noticed from the analysis that the technological advancement in E-commerce has a positive impact on E-Commerce revenues and it is expected to grow three-fold after by 2030.

Keywords: E-Commerce, Disruption, Drones, Technology, E-Retail 